\title{
Correlation between land-use change and greenhouse gas emissions in urban areas
}

\author{
C.-H. Liao $\cdot$ C.-L. Chang $\cdot$ C.-Y. Su $\cdot$ P.-T. Chiueh
}

Received: 25 May 2012/Revised: 24 October 2012/Accepted: 22 December 2012/Published online: 12 February 2013

(C) Islamic Azad University (IAU) 2013

\begin{abstract}
Urban areas are the main sources of greenhouse gas (GHG) emissions. Previous studies have identified the effectiveness of better urban design on mitigating climate change and land-use patterns in cities as important factors in reducing GHG by local governments. However, studies documenting the link between land-use and GHG emissions are scant. Therefore, this study explores the driving forces of land-use change and GHG emission increments in urban areas and investigates their correlations. The study area, Xinzhuang, is a satellite city of Taipei that has rapidly urbanized in the past few decades. Twenty-one potential variables were selected to determine the driving forces of land-use change and GHG emission increments by binomial logistic regression based on the investigation data of national land use in 1996 and 2007. The correlation of land-use change and GHG increments was examined by Spearman rank-order analysis. Results of logistic regression analysis identified that population and its increasing density rate are main driving forces on both land-use
\end{abstract}

Electronic supplementary material The online version of this article (doi:10.1007/s13762-012-0155-2) contains supplementary material, which is available to authorized users.

C.-H. Liao - C.-Y. Su

Graduate Institute of Environmental Engineering, National

Taiwan University, No. 71 Chou-Shan Rd., Taipei 106, Taiwan

C.-L. Chang

Faculty of Department of Water Resources Engineering and Conservation, Feng Chia University, No. 100 Wenhwa Rd., Seatwen, Taichung 40724, Taiwan

P.-T. Chiueh $(\bowtie)$

Faculty of Graduate Institute of Environmental Engineering, National Taiwan University, No. 71 Chou-Shan Rd.,

Taipei 106, Taiwan

e-mail: ptchueh@ntu.edu.tw change and GHG increments. The Spearman rank correlation matrix indicates that fluctuating urbanization level is significantly correlated with the increase of total GHG emissions, the emissions of residence, commerce, and transportation sectors in neighborhoods; and the emissions of residence and transportation sectors seem closely connected to current urbanization level. The findings suggest that relationships among land-use, urbanization, and GHG emissions in urban areas vary greatly according to residence and transportation characteristics. Land-based mitigation may provide the most viable mechanism for reducing GHG emissions through residence and transportation sectors.

Keywords Binominal logistic regression - Driving force analysis · Greenhouse gas inventory - Land-use classification - Spearman rank-order correlation

\section{Introduction}

Greenhouse gas footprints in cities have received recent attention because several studies have demonstrated that better urban design could reduce carbon emissions more than alternative fuels, vehicles, and electricity generation (Hillman and Ramaswami 2010; Marshall 2008). Smart growth for urban areas with good public transport systems could reduce the number of miles traveled per vehicle, thus reducing GHG emissions (Chatterjee 2009; Hoornweg et al. 2011). Cities are considered the optimum scale for integrating policy development and action on mitigating climate change (Hoornweg et al. 2011; Ramaswami et al. 2008). Land-use patterns and urbanization in cities affect resident lifestyles, and thus, GHG emissions (Stone 2009). Therefore, enhanced understanding of the determinants of 
land-use change in urban areas is necessary to assess the effect of urbanization on the environment and to manage GHG emissions in cities.

Land-use change patterns result from complex interactions between humans and the physical environment and are continually changing; therefore, the logistic regression method is widely used to determine the driving forces of land-use change from potential impact factors (Lin et al. 2008; Styers et al. 2010; Verburg et al. 2004; Wyman and Stein 2010). Wyman and Stein (2010) used the binomial logistic model to assess deforestation drivers from social survey and land-cover change data within an protected area in Belize. Their results presented a basis for numerous hypotheses on the processes driving land-use change within the study area.

Land-use data from satellite images are often retrieved and compared for different periods (Cetin 2009; Lin et al. 2008; Verburg et al. 2004). For presenting the change of land-use type, a certain area or image grids are often adopted as analysis scales, such as $500 \mathrm{~m} \times 500 \mathrm{~m}$ (Verburg et al. 2004). However, the land-use policy and the data of potential driving factors for land-use change are established based on administrative jurisdiction. The neighborhood-scale for quantifying change of land-use is also commonly used in driving forces analysis (Lee et al. 2009). Several studies have grouped neighborhoods into complete landscape structure units and used the indices of landscape ecology to quantify characteristics, structure, and layouts of spatial configurations (Lee et al. 2009; Lin et al. 2008; Verburg et al. 2004).

Implementing programs of reducing GHG emissions should begin with a good understanding of emission sources. GHG inventories for local authorities often identify emissions by source and report them in per capita terms (Hoornweg et al. 2011; Ramaswami et al. 2008). Local GHG emission accounting is typically limited by data availability. If urban GHG inventories follow a procedure similar to the Intergovernmental Panel on Climate Change (IPCC) methodology for national inventories (IPCC 2006), the direct emission from Scope 1 of local inventories can mesh with national inventories. By identifying sectors with high emission rates, including urban material production, local jurisdictions can determine where best to mitigate emissions and link to national policies for sectors (Hoornweg et al. 2011). The IPCC proposed an agreement to inventory urban GHG emissions to establish a common standard, and suggested that urban GHG inventories include (1) out-of-boundary emissions from electricity generation and district heating consumed in cities, (2) emissions from aviation and marine vessels carrying passengers or freight away from cities, and (3) out-of-boundary emissions from waste generated in cities (UNEP/UN-HABITAT/World Bank 2010). In Taiwan, the national inventory has been established and is updated regularly (Liu et al. 2012), whereas county-scale GHG emission inventories are only established for some municipalities. Both national and county-scale inventories follow IPCC guidelines (2006); however, some data are currently unavailable for the county scale.

Although several studies mentioned the driving forces and follow-up effects of land-use change and recent literature identified city-scale GHG emission footprints, studies exploring the difference between the driving forces of landuse change and GHG emission increments are scant. Neither the correlation of changing urbanization levels nor GHG increments have been discussed. This study determines the drivers of land-use change and GHG increase in urban areas by neighborhood scale and explores the correlations between them.

\section{Materials and methods}

Study site

The study area of Xinzhuang, situated within New Taipei City, is a typical urbanized satellite city of the Taiwan capital, Taipei (Fig. 1). Xinzhuang covers an area of approximately $20 \mathrm{~km}^{2}$ and is located within a flat plain. Its average precipitation is approximately $2,400 \mathrm{~mm}$ annually. Xinzhuang has one national scale and several county scale industrial parks. Currently, nearly 4,000 factories are operating in this city, and more than 6,000 factories were in operation during the most prosperous period. The population density of Xinzhuang reached 20,444 people per square kilometer in 2011 , from 15,621 people per square kilometer in 1991, with an overall increase of $30.9 \%$ in the past two decades. This rapid urbanization has resulted in rising energy consumption in Xinzhuang. To save energy and achieve emission reduction targets, Xinzhuang has adopted a series of mitigation measures and polices. Recently, it became the pilot city of the "low-carbon homelands" of New Taipei City, making Xinzhuang a particularly interesting case for the correlation analysis of GHG emissions and land-use change for urban areas. Most of the land in Xinzhuang was agrarian in the 1970s, but it has transformed into an industrial and commercial district, following the abandonment of factories in the 1990s. Xinzhuang comprises 71 neighborhoods, which are the basic units of city administration in Taiwan and are often used as analytical units in addressing environmental concerns. Neighborhoods are also used as analytical units in this study.

Land-use change analysis

Several assumptions were used in determining change patterns: (1) land-use change in each neighborhood is 
Fig. 1 Study site

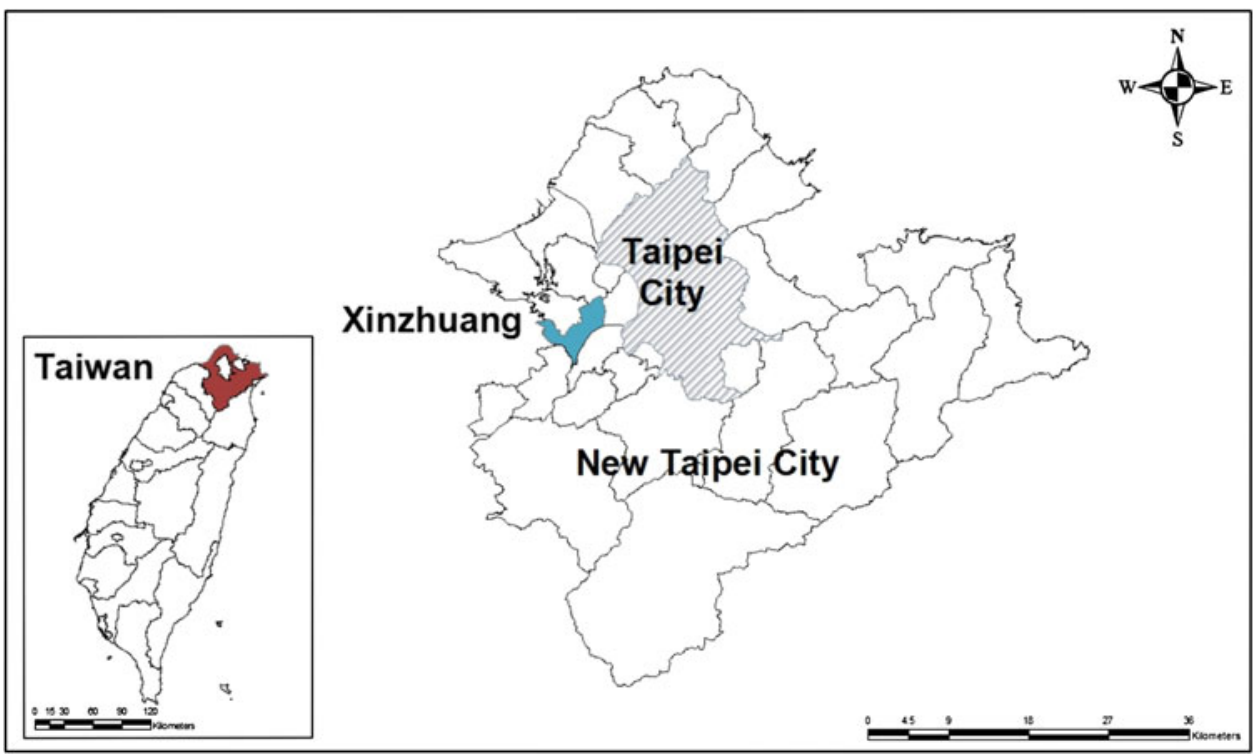

independent; each neighborhood has a complete landscape structure, (2) each neighborhood is composed of patches, corridors, and matrices (Forman 1995), and (3) land-use change in neighborhoods is considered in changing urbanization levels.

\section{Land-use data}

Land-use data were obtained from the National Land Surveying and Mapping Center, Taiwan (Taiwan: National Land Surveying and Mapping Center 2011) and clipped into the neighborhood scale of the study area. The Center conducted the first nationwide land-use investigation during 1993-1995 using a field survey. The second investigation was conducted during 2006-2008 based on non-cloud aerial photographs and SPOT-5 satellite images. For consistency with other statistical data, the temporal scales of these two land-use data sets were defined as 1996 and 2007. Land-use types of built-up land (including residence and industry/commerce areas), public use land (including government organizations, hospitals, schools), and recreational land were retrieved to represent the urban land cover and land-use type.

\section{Classification of urbanization levels}

To quantify changes to land-use patterns, landscape indices were calculated using Patch Analyst 4.0 for ArcGIS 9.3 (Patch Analyst Manual 1999; Paudel and Yuan 2012). Seven landscape indices_-patch density (PD), mean shape index (MSI), mean patch fractal dimension (MPFD), edge density (ED), road density (RD), built-up density (BD), and green land (GL) - were used to present land-use composition and configuration at the landscape level in each neighborhood. Table 1 provides a summary of adopted indices.

The results of patch analysis for 71 neighborhoods of the study area in 1996 and 2007 were used to classify urbanization levels of neighborhoods by cluster analysis. Cluster analysis encompasses different algorithms and methods for grouping similar objects into respective categories (Owen et al. 2006). In this study, the Euclidean distance (Eq. 1) was used as the dissimilarity indices coefficient, and the Ward method was used to minimize the error increase in sum of squares (variance) resulting from clustering.

$\mathrm{SS}=\sum_{i=1}^{p} \sum_{j=1}^{m}\left(x_{i j}-\bar{x}_{i}\right)^{2}$

where SS is the squared Euclidean distance, $x_{i j}$ is the value of index $i$ in neighborhood $j, x_{i}$ is the average of index $i$ of all neighborhoods, $p$ is the number of indices, and $m$ is the number of neighborhoods.

\section{Driving forces of land-use change}

For determining the driving force of land-use change, 21 potential variables were selected based on socioeconomic conditions, spatial policies, and natural features in the study area (see Table 2).

Logistic regression is widely used to analyze the driving forces of land-use change (Lin et al. 2008; Verburg et al. 2004). The logistic model quantifies predictor effect in a log odds ratio using maximum likelihood estimation (Eq. 2). Stepwise logistic regression was used to estimate the coefficients of the defined model (Eq. 3). The dependent variable is a binary (presence or absence) event, which means that the statistical model is a binomial logistic 
Table 1 Land-use classification indicators used in this study

\begin{tabular}{|c|c|c|c|}
\hline Landscape structure & Indicators & Definition & Note \\
\hline \multirow[t]{8}{*}{ Patch } & \multirow[t]{2}{*}{ Patch density, PD } & \multirow{2}{*}{$\mathrm{PD}=\frac{\mathrm{NP}}{\mathrm{A}}$} & NP: patch numbers \\
\hline & & & A: area of a selected neighborhood \\
\hline & \multirow[t]{2}{*}{ Mean shape index, MSI } & $\sum^{m} \sum^{n} \frac{p_{\mathrm{i}}}{2 \sqrt{\pi}}$ & $a_{i j}:$ area of $j$ th patch in classification $i$ \\
\hline & & $\mathrm{MSI}=\frac{{ }_{i=1} n_{j=\mathrm{i}} \mathrm{V}}{n_{i}}$ & $p_{i j}:$ perimeter of $j$ th patch in classification $i$ \\
\hline & \multirow{2}{*}{$\begin{array}{l}\text { Mean patch fractal } \\
\text { dimension, MPFD }\end{array}$} & $\sum^{n}\left(\frac{2 \ln p_{i j}}{\ln _{a j}}\right)$ & $n_{i}$ : patch numbers of classification $i$ \\
\hline & & $\mathrm{MPFD}=\frac{j=1}{n_{i}}$ & $\begin{array}{l}p_{i j}: \text { perimeter of } j \text { th patch in classification } i \\
a_{i j}: \text { area of } j \text { th patch in classification } i\end{array}$ \\
\hline & \multirow[t]{2}{*}{ Edge density, ED } & $\mathrm{ED}=\sum_{k=1}^{m}$ & $\begin{array}{l}e_{i k}: \text { total edge length between classification } i \text { and } \mathrm{c} \\
\text { lassification } k\end{array}$ \\
\hline & & & $A$ : area of a selected neighborhood \\
\hline \multirow[t]{2}{*}{ Corridor } & \multirow[t]{2}{*}{ Road density, RD } & \multirow{2}{*}{$\mathrm{RD}=\frac{R_{\mathrm{L}}}{A}$} & $\mathrm{R}_{\mathrm{L}}$ : total length of main roads \\
\hline & & & $A$ : area of a selected neighborhood \\
\hline \multirow[t]{3}{*}{ Matrix } & \multirow[t]{2}{*}{ Build-up density, BD } & \multirow[t]{2}{*}{$\mathrm{BD}=\frac{\mathrm{B}_{\text {area }}}{A}$} & $B_{\text {area }}:$ total area of build-ups \\
\hline & & & A: area of a selected neighborhood \\
\hline & Green land, GL & & \\
\hline
\end{tabular}

Table 2 Potential driving force variables of land-use change

\begin{tabular}{|c|c|c|}
\hline & Variables & Description \\
\hline \multirow{14}{*}{$\begin{array}{l}\text { Socioeconomic } \\
\text { variables }\end{array}$} & $X 1$ & Population in 1996 \\
\hline & $X 2$ & Population in 2007 \\
\hline & $X 3$ & Population density in 1996 \\
\hline & $X 4$ & Population density in 2007 \\
\hline & $X 5$ & The increase rate from $X 3$ to $X 4$ \\
\hline & $X 6$ & Industry and commerce areas in 1996 \\
\hline & $X 7$ & Industry and commerce areas in 2007 \\
\hline & $X 8$ & The increase rate from $X 6$ to $X 7$ \\
\hline & $X 9$ & The decrease rate of agrarian areas \\
\hline & $X 10$ & Road density \\
\hline & $X 11$ & $\begin{array}{l}\text { Distance to the nearest highway } \\
\text { entrance }\end{array}$ \\
\hline & $X 12$ & Distance to the nearest downtown area \\
\hline & $X 13$ & Distance to the nearest railway station \\
\hline & $X 14$ & $\begin{array}{l}\text { Distance to nearest metropolitan } \\
\text { transportation station }\end{array}$ \\
\hline \multirow{6}{*}{$\begin{array}{l}\text { Spatial } \\
\text { variables }\end{array}$} & $X 15$ & Within urban planning areas \\
\hline & $X 16$ & $\begin{array}{l}\text { Within } 800 \mathrm{~m} \text { service area of } \\
\text { metropolitan transportation system }\end{array}$ \\
\hline & $X 17$ & Having at least one elementary school \\
\hline & $X 18$ & Having at least one park \\
\hline & $X 19$ & Having at least one industrial park \\
\hline & $X 20$ & School density \\
\hline Natural variable & $X 21$ & Elevation \\
\hline
\end{tabular}

model with two choices: convert each neighborhood into a land-use change occurrence (1) or not (0). Using the results, the following regression through odds ratio analysis can be specified:

$$
\begin{aligned}
P(y= & 1 \mid 1 \text { and }- \text { use changed, } y=0 \mid 1 \text { and } \\
& \quad-\text { use unchanged }) \\
= & \frac{\mathrm{e}^{f(x)}}{1+\mathrm{e}^{f(x)}} \\
f(x)= & \beta_{0}+\beta_{1} X_{1}+\beta_{2} X_{2}+\cdots \beta_{k} X_{k}
\end{aligned}
$$

where $X_{i}$ is the variables of driving force, $\beta_{i}$ is the coefficients to be estimated, and $k$ is the number of variables.

Statistical significance tests for the overall model (Omnibus and Hosmer-Lemeshow tests) and the variables (Cox-Snell $R^{2}$ \& Nagelkerke $R^{2}$ tests) are applied to present the relationship between the models and data sets.

GHG emissions inventory

The sectoral GHG emissions inventory of Xinzhuang in 1996 and 2007 was estimated using the emission-factor method, according to the framework of C40 and ICLEI Global Protocol for Community-scale Greenhouse Gas Emissions (C40/ICLEI/WRI 2012; see Table S1 in the Supplementary Material). The values of emission factors used in this study refer to local data suggested in the Management Table of GHG Emission Factors V. 6.0 by the Taiwan: EPA (Environmental Protection Administration) (2011); most of the emission factors were extracted from the IPCC manual (2006). The three dominant GHGs $\left(\mathrm{CO}_{2}\right.$, $\mathrm{CH}_{4}, \mathrm{~N}_{2} \mathrm{O}$ ) that account for more than $97 \%$ of $\mathrm{GHG}$ emissions in Taiwan (Liou 2011) are inventoried and reported collectively as carbon dioxide equivalents $\left(\mathrm{CO}_{2} \mathrm{e}\right)$. No city-scale data are available for the three remaining halocarbon GHGs (HFCs, PFCs, and SF6). Inventory data were classified into residential, commercial, industrial, 
transportation, agriculture, waste, and forest carbon sink sectors. The inventory scopes included three parts: Scope 1 , direct emission from fuel combustion in each sector; Scope 2, indirect emission from electricity use in each sector; Scope 3, emission from waste treatment outside the study area. Scopes 1 and 2 emissions are determined in the Xinzhuang boundary. The activity data for residential, commercial, and industrial sectors were collected using a top-down approach, relying on data aggregated by national agencies. In the transportation sector, a bottom-up approach was used based on the local statistics of traffic volume and vehicle kilometers traveled. For the solid waste treatment sector, the actual quantity of municipal solid waste was used to estimate the GHG emission. Local statistics of the livestock industry were extracted to calculate the emissions. For exploring the correlation of GHG emission and land-use change, the GHG inventory of each sector was allocated to each neighborhood based on population, residential area, floor area of industry and commerce, number of factories and commercial stores, agricultural area, road length, and green land area.

Correlation between land-use change and GHG emission increments

The binomial logistic regression model and the variables used for determining driving forces of land-use change (21 variables, see Table 2) were also used to explore similar driving forces of increasing GHG emissions. The Spearman rank-order correlation method was used to investigate the increment relevance of GHG emissions and land-use change in each neighborhood (Styers et al. 2010).

\section{Results and discussion}

Land-use change

\section{Classification of urbanization levels}

According to the results of Patch analysis and cluster analysis, the 71 neighborhoods were classified into four urbanization levels based on the landscape indices: low, medium, medium-high, and high. Table 3 shows the comparison of indices average for each urbanization level and overall average for all neighborhoods.

Urban areas typically have more build-up, higher road density, and less green land than do rural areas. In the urbanizing process, economic development leads to a high demand for land. Consequently, build-up patches increase separately and rapidly. As economic development continues, build-ups connect and grow into a huge patch, resulting in smaller patch numbers. How patches gather in a selected area can be determined by discussing the PD, MPFD, and ED. In a low-developed area, PD is low, MPFD is trivial, and ED tends to be high. In contrast, in urbanized areas, PD, MPFD, and ED considerably differ from the low-developed area. However, a mature urban area may have low PD caused by patch gathering. Figure 2 shows the urbanization levels in Xinzhuang established by the land-use classification indicators, and shows that Xinzhuang developed from the northern and southern regions during this decade.

The upgrade of urbanization levels from 1997 to 2006 was classified into three patterns for follow-up discussion of the relation to GHG emissions. Urbanization levels

Table 3 Mean value of index at each urbanization level compared to the overall average index

\begin{tabular}{|c|c|c|c|c|c|c|c|c|}
\hline \multirow[t]{2}{*}{ Urbanization level } & \multicolumn{8}{|l|}{ Landscape index } \\
\hline & & $\mathrm{PD}$ & MSI & MPFD & $\mathrm{ED}$ & $\mathrm{BD}$ & $\mathrm{RD}$ & GL \\
\hline \multirow[t]{2}{*}{ Low } & mean & 93.46 & 1.52 & 1.48 & 0.077 & 0.244 & 0.011 & 340610.5 \\
\hline & Above/below average & - & + & - & - & - & - & + \\
\hline \multirow[t]{2}{*}{ Medium } & Mean & 151.36 & 1.52 & 1.56 & 0.065 & 0.616 & 0.015 & 12882.58 \\
\hline & Above/below average & - & + & + & - & + & - & - \\
\hline \multirow[t]{2}{*}{ Medium-high } & Mean & 404.37 & 1.5 & 1.61 & 0.111 & 0.629 & 0.029 & 584.54 \\
\hline & Above/below average & + & - & + & + & + & + & - \\
\hline \multirow[t]{2}{*}{ High } & Mean & 268.25 & 1.51 & 1.51 & 0.087 & 0.694 & 0.028 & 190.24 \\
\hline & Above/below average & + & - & - & + & + & + & - \\
\hline Overall average & 229.36 & 1.51 & 1.54 & 0.085 & 0.545 & 0.021 & 88566.97 & \\
\hline
\end{tabular}

Overall average means the average index in all neighborhoods in 1996 and 2007

"+" stands for a value above the overall average and "-" is below the overall average

$P D$ patch density, $M S I$ mean shape index, $M P F D$ mean patch fractal dimension, $E D$ edge density, $B D$ build-up density, $R D$ road density, and $G L$ green land 
Fig. 2 Land-use investigation results in Xinzhuang, 1996 and 2007. This figure shows the land-use levels in Xinzhuang classified into four urbanization levels (low, medium, mediumhigh, and high) by the land-use classification indicators in 1996 and 2007. Xinzhuang developed in the northern and southern regions during the decade

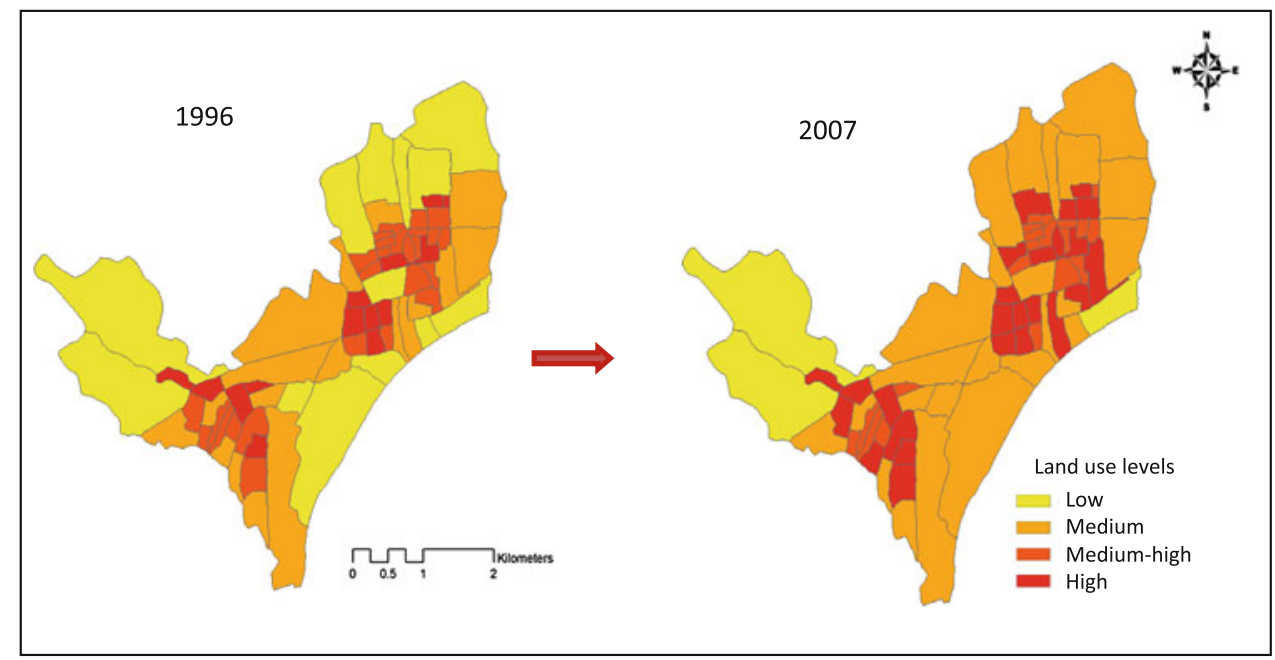

changing from lower to higher in this decade were classified into Change I (23 of 71 neighborhoods), which contains two situations: Change I-1 (from low to medium, medium-high, or high; 10 of 23 neighborhoods) and Change I-2 (from medium to medium-high or high; 13 of 23 neighborhoods), as shown in Fig. 3.

\section{Driving forces of land-use change}

To analyze the driving forces behind land-use change, the regression model that comprises nine of 21 potential variables is statistically significant, as determined by the
Omnibus test. The Cox-Snell $R^{2}$ test is 0.394 and the prediction rate is $81.7 \%$, which suggests good model fitting results. Based on the results in Table 4 , four variables explain the change of urbanization levels, $X 1$ (population in 1996), $X 3$ (population density in 1996), $X 5$ (population increase rate), and $X 14$ (distance to the nearest metro station). Among the socioeconomic factors, population has a major influence on the urbanization process. Population dynamics determine social flexibility, that is, people attract more people and significantly contribute to urbanization. Geographically, the main residential areas are located in the northern and southern parts of Xinzhuang. $X 14$, the

Fig. 3 Land-use change types in Xinzhuang from 1996 to 2007. If urbanization levels have changed from lower to higher in the decade, these cases belong to Change I. Meanwhile, Change I includes two situations: Change I-1 (from low to medium, medium-high, or high) and Change I-2 (from medium to medium-high or high)
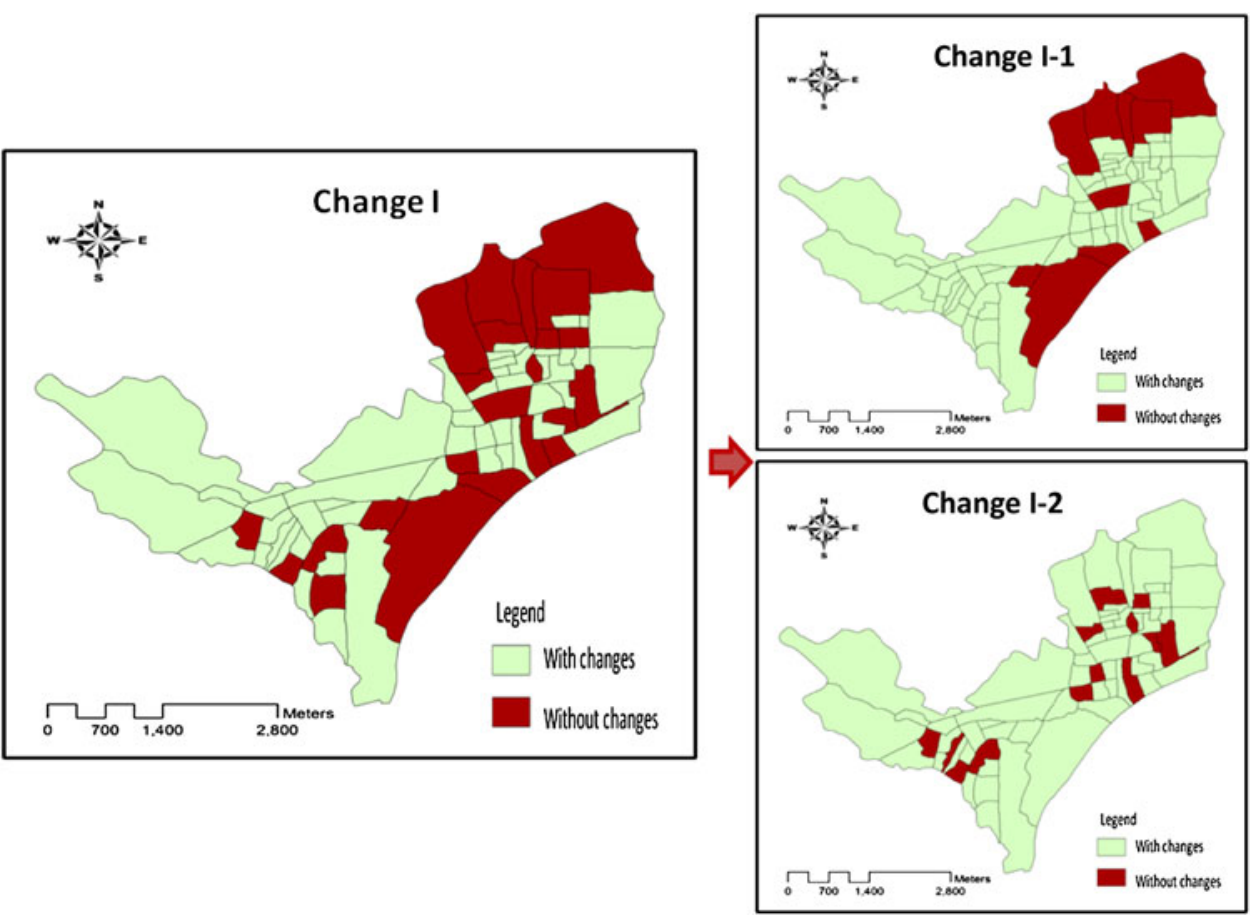
Table 4 Binomial logistic coefficients between land use and determinable driving force variables

\begin{tabular}{|c|c|c|c|c|c|}
\hline Driving force variable & Coefficient (B) & SE & Wald & $p$ value & Exp (B) \\
\hline$X 1$ & 3.903 & 1.715 & 5.18 & $0.023 *$ & 49.575 \\
\hline$X 2$ & -4.042 & 2.268 & 3.177 & 0.075 & 0.018 \\
\hline$X 3$ & -2.666 & 0.975 & 7.483 & $0.006 * *$ & 0.07 \\
\hline$X 5$ & 2.508 & 1.223 & 4.206 & $0.040^{*}$ & 12.277 \\
\hline$X 6$ & -1.128 & 0.76 & 2.205 & 0.138 & 0.324 \\
\hline$X 8$ & 0.487 & 0.367 & 1.762 & 0.184 & 1.628 \\
\hline$X 13$ & 0.853 & 0.494 & 2.978 & 0.084 & 2.347 \\
\hline$X 14$ & -1.237 & 0.483 & 6.561 & $0.010^{*}$ & 0.29 \\
\hline$X 17$ & 0.869 & 0.704 & 1.523 & 0.217 & 2.385 \\
\hline Constant & -1.796 & 0.609 & 8.687 & $0.003 * *$ & 0.166 \\
\hline Likelihood-ratio tests for the overall model & $\begin{array}{l}\text { Omnibus test }\left(\chi^{2}\right)=35.548 \\
\text { Hosmer-Lemeshow }=13.905\end{array}$ & & $\begin{array}{l}p=0.000(<0.05) \\
p=0.084(>0.05)\end{array}$ & & \\
\hline Likelihood-ratio tests for the variables & $\begin{array}{l}\text { Cox-Snell } \mathrm{R}^{2}=0.394 \\
\text { Nagelkerke } R^{2}=0.546\end{array}$ & & Prediction rate: $81.7 \%$ & & \\
\hline
\end{tabular}

$X 1$ is population in 1996, $X 2$ is population in 2007, $X 3$ means population density in 1996, $X 5$ means the population increase rate from 1996 to 2007, $X 6$ is industry and commerce areas in 1996, X8 means the increase rate of industry and commerce areas from 1996 to $2007, X 13$ is distance to the nearest railway station, $X 14$ means distance to the nearest monorail station and $X 17$ is enrichment with at least one elementary school

Bold values indicate the driving force variables that are significantly correlated to the change of urbanization levels

* Significance level of $5 \%(p \leq 0.05)$

** Significance level of $1 \%(p \leq 0.01)$

distance to the nearest metro station, is indicated as a major driving force of land-use change, because accessibility and urban expansion have a strong correlation.

\section{GHG emissions inventory}

\section{Sector-emission analysis}

Table 5 shows the GHG emission inventory of each sector in 1996 and 2007 in Xinzhuang including the waste treatment emissions outside the study area (Scope 3). The average emission was 10.69 ton- $\mathrm{CO}_{2} \mathrm{e} /$ capita in 1996 and 14.49 ton- $\mathrm{CO}_{2} \mathrm{e} /$ capita in 2007 (increasing $35.62 \%$ ). Compared to the average emission of Taiwan in 2007,

Table 5 GHG emission for sectors

\begin{tabular}{lllr}
\hline Sector & $\begin{array}{l}1996 \\
\left(\mathrm{t}-\mathrm{CO}_{2} \mathrm{e} / \text { year }\right)\end{array}$ & $\begin{array}{l}2007 \\
\left(\mathrm{t}-\mathrm{CO}_{2} \mathrm{e} / \text { year}\right)\end{array}$ & Variation \\
\hline Residence & $333,129.51$ & $601,918.15$ & 80.69 \\
Industry & $2,792,732.63$ & $4,044,157.62$ & 44.81 \\
Commerce & $205,058.61$ & $319,487.78$ & 55.80 \\
Transportation & $194,825.68$ & $728,107.53$ & 273.72 \\
Agriculture/Forestry & 1800.93 & 969.21 & -46.18 \\
Waste treatment & $179,560.64$ & $64,088.27$ & -64.31 \\
Carbon sink & $2,554.42$ & $2,392.59$ & -6.34 \\
Total emissions & $3,704,553.56$ & $5,756,335.95$ & 55.39 \\
Per capita emission & 10.69 & 14.49 & 35.62 \\
\hline
\end{tabular}

12.08 ton- $\mathrm{CO}_{2} \mathrm{e} /$ capita, the GHG emission of per capita in the study site is high. In the comparative study by Hoornweg et al. (2011), 14.49 ton- $\mathrm{CO}_{2} \mathrm{e} /$ capita in 2007 for Xinzhuang is also higher than most cities in developing countries, such as Shanghai in China (11.7 ton- $\mathrm{CO}_{2} \mathrm{e} /$ capita in 2006). Emissions from the industrial sector in 1996 and 2007 contributed nearly $70 \%$ to the total emission, followed by residence, transportation, and commerce sectors. The emissions contributed by agriculture and forestry sectors are relatively low. Compared to the variation rate of sectors during the decade, all sectors have a positive emission increase, excluding agriculture and forestry sectors. Emission from the transportation sector increased $274 \%$ and the residence sector increased $80 \%$, probably because emission from transportation increases with economic growth. An emission increase from the residence sector in the study site may be because of rapid population growth of $13 \%$ (from 350,000 to 390,000), increased electricity use per household, and the increased emission factor of electricity [from $0.531 \mathrm{~kg}-\mathrm{CO}_{2} \mathrm{e} / \mathrm{kWh}$ to $0.637 \mathrm{~kg}-\mathrm{CO}_{2} \mathrm{e} / \mathrm{kWh}$, Taiwan: Bureau of Energy (2012)]. In the waste treatment sector, GHG emission decreased $64 \%$ in the decade because landfill treatment was replaced by incineration and because of a highly efficient resource reduction of municipal solid waste in Taiwan. This Scope 3 emission contributed to the total GHG emission from $5 \%$ in 1996 to $1 \%$ in 2007 and confirms the viewpoints of Hoornweg et al. (2011) of a strong correlation between 
Table $6 \mathrm{CO}_{2}$ emissions inventory of Xinzhuang in 1996 and 2007

\begin{tabular}{|c|c|c|c|c|c|c|c|}
\hline GPC No & IPCC class & Scope & GHG emissions sources & $\begin{array}{l}\mathrm{CO}_{2} \mathrm{e}(1996) \\
\text { ton/year }(\%)^{*}\end{array}$ & $(\%)^{* *}$ & $\begin{array}{l}\mathrm{CO}_{2} \mathrm{e}(2007) \\
\text { ton/year }(\%)^{*}\end{array}$ & $(\%)^{* *}$ \\
\hline I. & & & Stationary units & & & & \\
\hline I. 1 & & & Residential buildings & & 9.0 & & 10.4 \\
\hline I.1.1 & $1 \mathrm{~A} 4 \mathrm{~b}$ & 1 & Direct emissions & $76,727(23)$ & & $90,435(15)$ & \\
\hline I.1.2 & & 2 & Energy indirect emissions & $256,402(77)$ & & $511,483(85)$ & \\
\hline I. 2 & & & Commercial/institutional facilities & & 5.5 & & 5.5 \\
\hline I. 2.1 & $1 \mathrm{~A} 4 \mathrm{a}$ & 1 & Direct emissions & $25,462(12)$ & & $67,791(21)$ & \\
\hline I. 2.2 & & 2 & Energy indirect emissions & $179,597(88)$ & & $251,696(79)$ & \\
\hline I. 4 & & & Industrial Energy Use & & 75.3 & & 69.7 \\
\hline I.4.1 & $1 \mathrm{~A} 2+1 \mathrm{~A} 5+1 \mathrm{~A} 4 \mathrm{c}$ & 1 & Direct emissions & $1,565,819(56)$ & & $1,721,799(43)$ & \\
\hline I. 4.2 & & 2 & Energy indirect emissions & $1,226,914(44)$ & & $2,322,358(57)$ & \\
\hline II. & & & Mobile units & & 5.3 & & 12.5 \\
\hline II.1 & & & On-road transportation & & & & \\
\hline II.1.1 & $1 \mathrm{~A} 3 \mathrm{~b}$ & 1 & Direct emissions & 194,826 & & 728,108 & \\
\hline III. & & & Waste & & 4.8 & & 1.9 \\
\hline III.1 & & & Solid waste disposal & & & & \\
\hline III.1.3 & & 3 & $\begin{array}{l}\text { Indirect emissions from community wastes } \\
\text { deposited in landfills located outside the } \\
\text { community boundary }\end{array}$ & 51,988 & & 8,329 & \\
\hline III.4 & & & Incineration and open burning & & & & \\
\hline III.4.2 & & 3 & $\begin{array}{l}\text { Indirect emissions from incineration and open } \\
\text { burning of wastes outside the community } \\
\text { boundary }\end{array}$ & 127,573 & & 55,759 & \\
\hline V. & & & Agriculture, forestry, and land use (AFOLU) & & 0.049 & & 0.017 \\
\hline \multirow[t]{5}{*}{ V.1 } & 3 & 1 & Direct emissions from AFOLU & 1,801 & & 969 & \\
\hline & & & GPC 2012 EXPANDED (tCO2e) & $3,707,109$ & 100.0 & $5,806,157$ & 100.0 \\
\hline & & & Scope1 & $1,864,635$ & 50.3 & $2,609,102$ & 45.0 \\
\hline & & & Scope 2 & $1,662,913$ & 44.9 & $3,085,537$ & 53.1 \\
\hline & & & Scope 3 & 179,561 & 4.8 & 111,518 & 1.9 \\
\hline
\end{tabular}

* Scope percentages in the same IPCC class

** Percentages in GPC 2012 EXPANDED

high GHG emission rates and solid waste generation. The carbon sink decreased slightly in the agriculture/forestry sector in the decade because of a small area of cultivated land that changed to build-up. The emission scope of each sector and the proportion of each scope in each sector are listed in Table 6.

According to Ramaswami et al. (2008), including essential urban materials (e.g., food, water, fuel, and concrete) enables cities to report separately the GHG impact associated with the direct end-use of energy by cities and the influence of extra-boundary activities that produce key urban materials. Such inclusion can also initiate city-scale GHG mitigation policies such as green concrete and urban transportation allocation procedures. Although only the waste treatment emissions in Scope 3 were considered in this study, the finding regarding the rapid increases of $\mathrm{GHG}$ emissions from residential and transportation sectors reveals the importance of investigating further the emissions caused by producing key urban materials and spatial allocating space for trans-boundary vehicle distances in the entire study area.

This study conducted the GHG emission inventory by following the community-based GHG emissions framework proposed by C40/ICLEI/WRI (2012). This framework, the Global Protocol for Community-Scale GHG (GPC), provides a standardized approach for helping cities quantify their GHG emissions to manage and reduce their GHG impacts. The GPC involves adopting the scope framework to delineate the distinction between direct and indirect emissions by emphasizing the relationship between city and national inventories. Regional transportation systems, waste disposal, and exchanges of goods and services are examples of activities that may be shared between cities and are included in the Scope 3 categories of GPC 
Table 7 GHG emission for sectoral-inventory

\begin{tabular}{|c|c|c|c|}
\hline Emission & Sector & 1996 & 2007 \\
\hline \multirow{4}{*}{$\begin{array}{l}\text { Area emission } \\
\left(\mathrm{t}-\mathrm{CO}_{2} \mathrm{e} / \mathrm{m}^{2} \text {-year }\right)\end{array}$} & Residence & 0.0956 & 0.1312 \\
\hline & Industry & 0.7626 & 1.4252 \\
\hline & Commerce & 0.1346 & 0.1553 \\
\hline & Agriculture and forestry & 0.0014 & 0.0009 \\
\hline $\begin{array}{l}\text { Length emission } \\
\left(\mathrm{t}-\mathrm{CO}_{2} \mathrm{e} / \mathrm{m} \text {-year) }\right.\end{array}$ & Transportation & 0.7265 & 2.7152 \\
\hline Per capita emission & Residence & 0.9611 & 1.5157 \\
\hline (t- $\mathrm{CO}_{2} \mathrm{e} /$ capita-year) & Waste treatment & 0.5180 & 0.1614 \\
\hline
\end{tabular}

2012 EXPANDED, based on full consumption-based and production-based accounting. This approach is closely with the demand-centered, hybrid life-cycle methodology for the city-scale GHG inventory used in Ramaswami et al. (2008). Erickson and Lazarus (2012) discussed the GPC and suggested that removing industry from communityscale inventories could provide a greater focus on the GHG emission sources over which local governments wield unique and direct influence.

\section{Neighborhood-emission analysis}

Table 7 shows the GHG emissions of area, road length, and per capita, which were converted from the results of sectoremission analysis of GHG, land-use data, and population in the study area. The area emission (in per $\mathrm{m}^{2}$ ) of the industrial sector was the highest and nearly ten times higher than the other sectors. Neighborhood-emission can be derived by multiplying these unit emissions by the area of each land-use type and population in each neighborhood. The neighborhood-emission shows that the total GHG emission is closely correlated to industrial sector emission rather than the urbanization level.

Correlation between land-use change and GHG emission increments

\section{Driving forces of GHG emission increments}

Similarly, the 21 potential drivers of land-use change were applied into the analysis of driving forces behind GHG emission change using binomial logistic analysis. Table 8 shows three significant variables of the 21 in the GHG driving force analysis. The Omnibus test $\left(\chi^{2}\right)$ is 29.724 and the $p$ value is $0.000(<0.05)$, which indicates that at least one variable can explain the increase in GHG emissions. The Hosmer-Lemeshow test also shows good model fit results. The Cox-Snell $R^{2}$ of 0.342 and the Nagelkerke $R^{2}$ of 0.456 suggest a significant low to medium correlation among the variables. Consequently, $X 1$ (population in 1996), $X 5$ (increased density rate from 1996 to 2007), and $X 8$ (increased rate of industrial and commercial areas from 1996 to 2007) account for the driving forces behind GHG increments in the binomial logistic regression analysis. High population areas in 1996 resulted in high population density, and both have a significant positive effect on GHG emissions. However, urbanization that leads to more industrial and commercial areas also caused more GHG emissions. Relative to the previous results of land-use change, $X 1$ (population in 1996) and $X 5$ (increased density rate from 1996 to 2007) are the common driving forces of land-use change and GHG emissions.

Table 8 Binomial logistic coefficients between GHG emissions and the determinable driving force variables

\begin{tabular}{|c|c|c|c|c|c|}
\hline Driving force variable & Coefficient (B) & SE & Wald & $p$ value & $\operatorname{Exp}(\mathrm{B})$ \\
\hline$X 1$ & 0.406 & 0.195 & 4.333 & $0.037 *$ & 1.502 \\
\hline$X 5$ & 0.047 & 0.018 & 6.623 & $0.010 * *$ & 1.048 \\
\hline$X 6$ & 15.469 & 6.209 & 6.206 & 0.157 & 222758.49 \\
\hline$X 8$ & 0.487 & 10.001 & 2.005 & 0.013* & 411740.13 \\
\hline Constant & -2.904 & 1.03 & 7.944 & $0.005 * *$ & 0.055 \\
\hline Likelihood-ratio tests for the overall model & $\begin{array}{l}\text { Omnibus test }\left(\chi^{2}\right)=29.724 \\
\text { Hosmer-Lemeshow }=8.247\end{array}$ & & $\begin{array}{l}p=0.000 \\
\text { n.s. } p>0.05\end{array}$ & & \\
\hline Likelihood-ratio tests for the variables & $\begin{array}{l}\text { Cox-Snell } R^{2}=0.342 \\
\text { Nagelkerke } R^{2}=0.456\end{array}$ & & Prediction rate: $80.3 \%$ & & \\
\hline
\end{tabular}

$X 1$ is population in 1996, $X 5$ represents the increasing population rate from 1996 to 2007, $X 6$ is industry and commerce areas in 1996 and $X 8$ means the increasing rate of industry and commerce areas from 1996 to 2007

Bold values indicate the driving force variables that are significantly correlated to the GHG emissions

* Significance level of $5 \%(p \leq 0.05)$

** Significance level of $1 \%(p \leq 0.01)$ 
Table 9 Significant Spearman correlation coefficients: GHG emission increments and land-use changes

\begin{tabular}{|c|c|c|c|c|c|c|c|}
\hline Land-use change & Total GHG emissions & Resident & Industry & Commerce & Transportation & Agriculture and forestry & Waste \\
\hline Change I & $0.343 * *$ & -0.022 & 0.14 & 0.128 & -0.141 & -0.057 & $0.341 * *$ \\
\hline \multicolumn{8}{|l|}{ Coefficient } \\
\hline Significance & 0.003 & 0.855 & 0.245 & 0.289 & 0.242 & 0.638 & 0.004 \\
\hline Change I-1 & $0.240 *$ & $-0.285 *$ & $0.267 *$ & $0.244 *$ & $-0.399 * *$ & -0.125 & $0.411 * *$ \\
\hline \multicolumn{8}{|l|}{ Coefficient } \\
\hline Significance & 0.044 & 0.016 & 0.025 & 0.04 & 0.001 & 0.298 & 0 \\
\hline Change I-2 & 0.125 & $0.303 *$ & -0.221 & -0.14 & $0.262 *$ & -0.185 & -0.03 \\
\hline \multicolumn{8}{|l|}{ Coefficient } \\
\hline Significance & 0.298 & 0.01 & 0.064 & 0.246 & 0.028 & 0.123 & 0.805 \\
\hline 1996LU & -0.009 & $0.502 * *$ & $-0.369 * *$ & $-0.251 *$ & $0.678 * *$ & $0.259 *$ & $-0.719 * *$ \\
\hline \multicolumn{8}{|l|}{ Coefficient } \\
\hline Significance & 0.942 & 0 & 0.002 & 0.035 & 0 & 0.029 & 0 \\
\hline 2007LU & 0.147 & $0.529 * *$ & $-0.348 * *$ & -0.222 & $0.594 * *$ & 0.206 & $-0.500 * *$ \\
\hline \multicolumn{8}{|l|}{ Coefficient } \\
\hline Significance & 0.22 & 0 & 0.003 & 0.063 & 0 & 0.085 & 0 \\
\hline
\end{tabular}

Change I means that land use changed from lower and higher levels, which contains two types: Change I-1 (low to medium, medium-high, or high) and Change I-2 (medium to medium-high or high). In addition, 1996LU and 2007LU stand for urbanization levels in 1996 and 2007

Bold values indicate the GHG emission increments that are significantly correlated to the land-use changes

* The Spearman's rank correlation coefficient achieves a significance level of $5 \%(p \leq 0.05)$

** The Spearman's rank correlation coefficient achieves a significance level of $1 \%(p \leq 0.01)$

Spearman correlations of land-use change and GHG emission increments

A multivariate Spearman rank-order correlation matrix was constructed to explore the correlation between land-use change and GHG emission increments. Change I, Change I-1, Change I-2, and urbanization level in 1996 (1996LU) and 2007 (2007LU) were selected as potential variables. The Spearman correlation matrix results are shown in Table 9, which indicates the significant positive correlation between total GHG emissions and Change I and Change I-1. The correlation coefficients are 0.343 and 0.240 , respectively, indicating that the change of urbanization level may influence total GHG emissions, particularly when low urbanized areas transform into higher urbanized areas.

In the residence and transportation sectors, all variables except Change I show a significant correlation with GHG emissions. Change I-1 (urbanization level from low to higher) shows a significant negative correlation, whereas Change I-2 (urbanization level from medium to higher) displays significant positive correlation. Such results suggest that the urbanization process may slightly affect residential GHG emissions. However, when cities continue to develop and urbanization levels change from medium to high, residential GHG emissions synchronously increase. Therefore, urbanization levels tend to affect GHG emissions directly in well-developed urban areas.
In the industry and commerce sectors, Change I-1 (urbanization level upgrading from lower to higher) shows a positive correlation and 1996LU (urbanization level in 1996) shows significant negative correlation with GHG emissions, suggesting that low urbanized areas (such as industrial areas) may be high GHG emission sources and GHG emissions may increase in the early stage of urbanization. In the agriculture and forestry sectors, only 1996LU shows a significant positive correlation with GHG emission, which suggests that low urbanized areas have greater reduction capacity. In the waste treatment sector, all variables except Change I-2 show a significant correlation with GHG emissions. The positive coefficients of Change I and Change I-1, and the negative coefficients of 1996LU and 2007LU suggest that low urbanized areas contribute greater GHG emissions to waste treatment in urbanization processes. The overall result shows that only in residence and transportation sectors, urbanization levels (both 1996LU and 2007LU) exhibit a significant positive correlation with GHG emissions. Therefore, all GHG mitigation policies should include these two sectors to maximize reduction results. For local authorities, these results suggest that land-based mitigation efforts may provide mechanisms that are more viable for reducing emissions from the transportation and residential sectors. The mitigation effects caused by household action have been widely discussed recently; for example, Dietz et al. (2009) 
investigated the potential for near-term reductions using available technologies in U.S. homes and nonbusiness travel and estimated an achievable savings of $20 \%$ of household direct emissions, or $7.4 \%$ of U.S. national emissions. Adoption methods, such as upgrading equipment, reducing standby electricity, and replacing vehicles with higher fuel efficiency models, have been proposed to mitigate GHG emissions. In contrast, a high rate of GHG emissions from the industry sector may not be completely attributed to an industry-commerce mixed city, such as Xinzhuang, because the energy consumed during production should be allocated to products. Ramaswami et al. (2008) have proposed such a demand-centered, hybrid lifecycle methodology for city-scale greenhouse gas inventories.

\section{Conclusion}

This paper developed a classification system for determining urbanization levels and land-use change in the last decade (from 1996 to 2007), and explored the relationship between land-use change and GHG emissions for the study area. Low to high levels of urbanization in neighborhoods cause increased total GHG emissions and emissions from all sectors, excluding agriculture/forestry and waste treatment sectors. The correlation results show that GHG emissions from residence and transportation sectors correlated significantly with urbanization and could be locally addressed in GHG reduction. This study also examined the driving forces of land-use change and GHG emission increments. The results indicate that early-stage population and increased population density during the period are common factors of land-use change and GHG increments. Understanding the correlations of land-use and GHG emissions offers an important opportunity for local governments to mitigate climate change problems.

Acknowledgments The authors wish to thank the Taiwan National Science Committee for supporting this research. Funding for this research was provided by the Taiwan National Science Committee NSC99-2621-M002-012.

\section{References}

C40/ICLEI/WRI, (2012). Global Protocol for community-scale greenhouse gas emissions (GPC), pilot version-May 2012. Available at: http://www.ghgprotocol.org/files/ghgp/GPC_Pilot Version_1.0_May2012_20120514.pdf

Cetin M (2009) A satellite based assessment of the impact of urban expansion around a lagoon. Int J Environ Sci Tech 6(4):579-590

Chatterjee R (2009) Smart growth: a solution to climate change? Environ Sci Technol 43(6):1660
Dietz T, Gardner GT, Gilligan J, Stern PC, Vandenbergh MP (2009) Household actions can provide a behavioral wedge to rapidly reduce US carbon emissions. Proc Natl Acad Sci 106(44): 18452-18456

Erickson P, Lazarus M (2012) Revisiting community-scale greenhouse gas inventories. Environ Sci Technol 46(9):4693-4694

Forman RTT (1995) Land mosaics: the ecology of landscapes and regions. Cambridge University Press, Cambridge

Hillman T, Ramaswami A (2010) Greenhouse gas emission footprints and energy use benchmarks for eight U.S. cities. Environ Sci Technol 44(6):1902-1910

Hoornweg D, Sugar L, Trejos Gómez CL (2011) Cities and greenhouse gas emissions: moving forward. Environ Urban 23(1):207-227

IPCC, (2006). Guidelines for national greenhouse gas inventories. Available at http://www.ipcc-nggip.iges.or.jp/public/2006gl/ index.html

Lee CL, Huang SL, Chan SL (2009) Synthesis and spatial dynamics of socio-economic metabolism and land use change of Taipei Metropolitan Region. Ecol Model 220(21):2940-2959

Lin YP, Lin YB, Wang YT, Hong NM (2008) Monitoring and predicting land-use changes and the hydrology of the urbanized Paochiao watershed in Taiwan using remote sensing data, urban growth models and a hydrological model. Sensors 8(2):658-680

Liou HM (2011) A comparison of the legislative framework and policies in Taiwan's four GHG reduction acts. Renew Sustain Energy Rev 15(4):1723-1747

Liu CH, Lenzen M, Murray J (2012) A disaggregated emissions inventory for Taiwan with uses in hybrid input-output life cycle analysis (IO-LCA). Nat Resour Forum 36(2):123-141

Marshall JD (2008) Energy-efficient urban form. Environ Sci Technol 42(9):3133-3137

Owen SM, MacKenzie AR, Bunce RGH, Stewart HE, Donovan RG, Stark G, Hewitt CN (2006) Urban land classification and its uncertainties using principal component and cluster analyses: a case study for the UK West Midlands. Landsc Urban Plan 78(4):311-321

Patch Analyst Manual (1999) Patch Analyst User's Manual, a tool for quantifying landscape structure. NWST Technical Manual TM002

Paudel S, Yuan F (2012) Assessing landscape changes and dynamics using patch analysis and GIS modeling. Int J Appl Earth Obs 16:66-76

Ramaswami A, Hillman T, Janson B, Reiner M, Thomas G (2008) A demand-centered, hybrid life-cycle methodology for city-scale greenhouse gas inventories. Environ Sci Technol 42(17):64556461

Stone B (2009) Land use as climate change mitigation. Environ Sci Technol 43(24):9052-9056

Styers DM, Chappelka AH, Marzen LJ, Somers GL (2010) Developing a land-cover classification to select indicators of forest ecosystem health in a rapidly urbanizing landscape. Landsc Urban Plan 94(3-4):158-165

Taiwan: Bureau of Energy (2012) Energy statistical hand book. Available at http://web3.moeaboe.gov.tw/ECW/english/content/ SubMenu.aspx?menu_id=1537

Taiwan: EPA (Environmental Protection Administration) (2011) GHG emission factors V. 6.0. Available at http://ghgregistry. epa.gov.tw/Tool/tools.aspx

Taiwan: National Land Surveying and Mapping Center (2011) Land use investigation. Ministry of the Interior, Taiwan. Available at http://lui.nlsc.gov.tw/LUWeb/eng/Content_e.aspx

UNEP/UN-Habitat/World Bank (2010) Draft international standard for determining greenhouse gas emissions for cities. Available at http://www.unep.org/urban_environment/PDFs/InternationalStdGHG.pdf 
Verburg PH, van Eck JRR, de Nijs TCM, Dijst MJ, Schot P (2004)

Determinants of land-use change patterns in the Netherlands.

Environ Plan B 31(1):125-150
Wyman MS, Stein TV (2010) Modeling social and land-use/landcover change data to assess drivers of smallholder deforestation in Belize. Appl Geogr 30(3):329-342 